\title{
Endocranial Complications of Endoscopic Sinus Surgery: Learning from Experience
}

\author{
Miguel Armengot-Carceller ${ }^{1}$, Rosa Hernandez-Sandemetrio $^{2}$ \\ ${ }^{1}$ ENT Department, Surgery Department, Valencia University, General and University Hospital, \\ Valencia, Spain \\ ${ }^{2}$ ENT Department, General and University Hospital, Valencia, Spain \\ Email: ${ }^{*}$ miguel.armengot@gmail.com
}

Received 22 June 2014; revised 21 July 2014; accepted 20 August 2014

Copyright (C) 2014 by authors and Scientific Research Publishing Inc.

This work is licensed under the Creative Commons Attribution International License (CC BY). http://creativecommons.org/licenses/by/4.0/

(c) (i) Open Access

\begin{abstract}
Objectives: We critically reviewed our experiences in endocranial complications with Functional Endoscopic Sinus Surgery, and investigated the causes, prevention strategies and management. Methods: We conducted a retrospective study of endocranial complications with Functional Endoscopic Sinus Surgery performed during last 10 years in our ENT department. We analyzed endocranial complications, their causes, consequences, treatments and outcomes. Management was performed in collaboration with neurosurgeons and infectious diseases specialists. Results: Of 763 Functional Endoscopic Sinus Surgery procedures, we identified three cases with endocranial complications $(0.393 \%)$. These complications included: a case of postoperative severe cerebrospinal fluid leak in a patient treated for severe polyposis; a case of cerebral-frontal abscess with delayed clinical manifestation (4 weeks post-surgery) in a patient treated for chronic pansinusitis who experienced difficult surgery for septal spur; and a case of pneumocephalus in a patient treated for allergic fungal sinusitis. The clinical outcome was favorable in all cases. Conclusions: Intraoperative cerebrospinal fluid leak, anatomical deformities (even minimal deformities) and massive inflammatory sinus disease are predisposing factors for endocranial complications with Functional Endoscopic Sinus Surgery. Prognosis can be favorable when therapeutic management is carried out in collaboration with neurosurgeons and infectious disease specialists.
\end{abstract}

\section{Keywords}

Cerebral Abscess, Cerebrospinal Fluid Leak, Inflammatory Sinus Disease, Pneumocephalus, Polyposis

\footnotetext{
"Corresponding author.
} 


\section{Introduction}

Functional Endoscopic Sinus Surgery (FESS) is the therapeutic method of choice in surgical therapy of chronic sinusitis [1]-[4]. Although FESS is considered safe when performed by experienced surgeons [5] [6], complications continue to be reported despite technical and instrumental advances [1] [7]-[9]. These complications are divided into major and minor categories [1] [8] [10]: intra/postoperative and immediate/delayed [1] [5] [8] [10]. Major injuries and life-threatening endocranial complications include [1] involuntary penetration into the skull base, production of a cerebrospinal fluid (CSF) leak, meningitis, pneumocephalus and epidural or intracerebral abscess [1] [3] [5] [8] [9]. Knowledge of the mechanism of injury is essential for prevention, identification and immediate correction of these complications [2] [3] [5] [7].

The rise in FESS indications has resulted in an increase in endocranial complications [4]. However, defining the true incidence of these complications is impeded by significant variability of reports among authors [6] [8] [11].

To better understand how to avoid complications of FESS, we analyzed the causes, treatment and evolution of the endocranial complications secondary to FESS during the last ten years at our teaching hospital.

\section{Materials and Methods}

We performed a retrospective review of all FESS performed in our department between 2003 and 2012 and the reported cases of endocranial complications that occurred. Cases of endoscopic approach for endocraneal tumors were excluded. Each patient was examined using preoperative nasal endoscopy and computed tomography (CT) scan to determine the extent of disease and to ascertain the patients' anatomy and their particularities. An appropriate history was documented for each patient to establish a diagnosis and subsequent therapeutic indication (Table 1). All surgeries were performed using a $4 \mathrm{~mm}-30^{\circ}$ telescope, and endoscopic equipment with standard instrumentation. Navigation-assisted surgery was not available in our department.

Three cases with complications were identified. The surgeries in cases 1 and 3 were performed by the same experienced surgeon. The surgery in case 2 was started by a practitioner specialist and finished by another skilled surgeon. This study has been approved by the Ethics Committee of the Hospital.

\section{Results}

Of the 763 FESS performed, three endocranial complications (0.393\%) were registered (Table 1). Here, we summarize the three cases:

Patient 1: A 40-year-old male underwent FESS due to massive idiopathic polyposis with total occupation of the ethmoid cells and middle meatus and partial occupation of the maxilar, frontal and sphenoid sinus. Postoperatively, the patient developed a severe right CSF rhinorrhea. A CT scan revealed a bony defect with a wide communication from the nasal cavity to the anterior cerebral fossae (Figure 1(a)). After $24 \mathrm{~h}$, the fistula was repaired with a free flap of middle turbinate mucosa secured with fibrin glue (tissucol ${ }^{\circledR}$ ) and bioabsorbable material packing (Surgycel ${ }^{\circledR}$ ). Previously, a 2-mL 5\% fluorescein intrathecal injection was performed, according to our routine procedure [12]. The CSF leak was corrected immediately. The patient was treated by absolute rest and prophylactic antibiotics for 2 weeks, with a favorable evolution and without incidence. A CT study performed 30 days later demonstrated that the bone communication was repaired (Figure 1(b)).

Patient 2: A 41-year-old male underwent FESS due to pansinusitis with radiologic occupation of the entire paranasal sinus. During surgery, a CSF leak from the right anterior ethmoidal top was discovered, and an intraoperative repair was performed as describe above. The preoperative CT scan showed a deviated nasal septum that was not removed during surgery because it did not interfere with the approach to the ethmoid. However, this deviation confused the height position of the nasal fossae, and this confusion probably caused the rhinoliquorrhea. The patient was treated with absolute rest and received prophylactic antibiotics (amoxicillin-clavulanate 1 gr every 8 hours) for 1 week. At 7 days post-surgery, a cerebral and maxillofacial CT scan revealed no injury; however, at 1 month post-surgery, the patient presented to the emergency unit with confusional syndrome. An emergency CT showed a brain abscess in the left frontal region (Figure 2(a)). The abscess was evacuated by trepanation and treated with parenteral antibiotics for 3 months, adapted to the detected microorganism (Morganella Morgagnii) and in collaboration with the infectious disease Department: levofloxacin $500 \mathrm{mg}$ iv daily, metronidazole $1.5 \mathrm{~g}$ iv daily and ceftriaxone $2 \mathrm{~g}$ iv every 12 hours. After 2 months, a magnetic resonance image 
Table 1. Etiologic classification of cases (n: 763) (CSF: cerebrospinal fluid leak).

\begin{tabular}{cc}
\hline Diagnosis & Case number \\
\hline Nasal polyposis & $276(23 \%)$ \\
Sinusitis & $228(16.7 \%)$ \\
Antrochoanal polyp & $83(3 \%)$ \\
Esfenochoanal polyp & $2(0.26 \%)$ \\
Maxillary sinus cyst & $11(1.3 \%)$ \\
Cyst of rhinopharynx & $8(0.39 \%)$ \\
Mucocele & $30(1.4 \%)$ \\
Mucopiocele & $11(0.13 \%)$ \\
Sinus osteoma & $12(0.26 \%)$ \\
Concha bullosa & $6(0.78 \%)$ \\
Nasal synechia & $13(0.39 \%)$ \\
Nostril hemangioma & $14(0.52 \%)$ \\
CSF & $18(1.57 \%)$ \\
Rinolito & $4(0.52 \%)$ \\
Inverted papiloma & $15(0.65 \%)$ \\
Nasosinusal malignancy & $13(1.7 \%)$ \\
Tumor of the clivus & $5(0.26 \%)$ \\
Epistaxis & $8(0.39 \%)$ \\
Choanal atresia & $4(0.52 \%)$ \\
Sphenoid sinusitis & $2(0.26 \%)$ \\
\hline
\end{tabular}

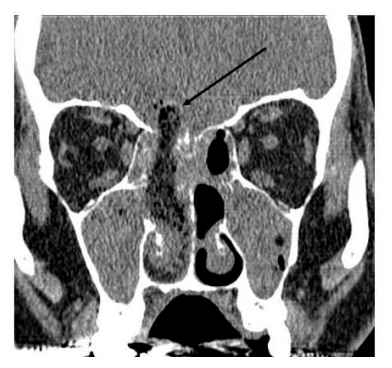

(a)

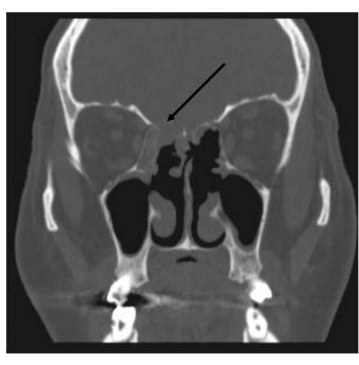

(b)

Figure 1. Patient 1. Computed tomography (CT) scan (coronal plane). (a) Osseus defect with a wide communication from the nasal to anterior cerebral fossae (arrow); (b) Bone communication repaired (arrow).

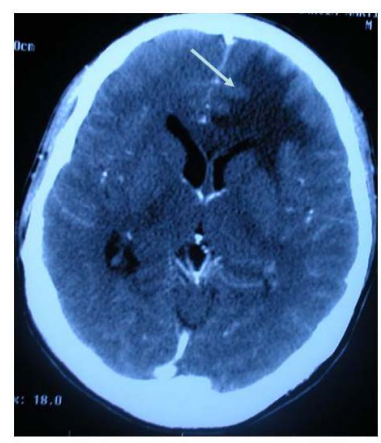

(a)

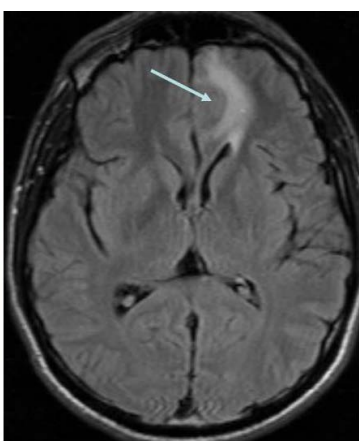

(b)

Figure 2. Patient 2. (a) Axial-plane CT showing a brain abscess in the left frontal lobe (arrow); (b) Axial plane of a magnetic resonance image demonstrated resolution of the cerebral abscess (arrow). 
(MRI) demonstrated resolution of the abscess (Figure 2(b)). The patient recovered and had no further problems.

Patient 3: A 42-year-old male underwent FESS due to allergic fungal rhinosinusitis. The preoperative CT and MRI demonstrated a pansinusitis with dehiscence of lateral wall of right sphenoid sinus due to his underlying pathology (Figure 3(a)).

In the immediate postoperative period, the patient suffered intense headache. The CT and MRI performed 24 $\mathrm{h}$ later showed a massive pneumocephalus in the frontal region (Figure 3(b)). A CSF leak was suspected. A revision surgery was performed using our usual technique, but no fistula was found. The patient was treated with antibiotic therapy (amoxicillin-clavulanate 1 gr every 8 hours) for 2 weeks and rest for 2 months. Follow-up care confirmed resolution of pneumocephalus without sequelae.

\section{Discussion}

FESS has become the standard surgical technique for the treatment of chronic sinusitis [13]; however, FESS is not without serious risks, mainly due to the anatomical complexities of the structures surrounding the sinuses (content ocular orbit, anterior cranial fossa, cavernous sinus and internal carotid artery) [2] [12]. Moreover, the operative field is formed by narrow slits with walls that bleed abundantly, sometimes only by contact with surgical instruments [8] [14].

The anatomical landmarks vary in each surgical patient and are dependent on the different degrees of pneumatization of the paranasal sinus [14]; thus, preoperative CT is important [9] [10] [14] [15]. To prevent anatomical damage, surgeons must be mindful of the anatomical areas most at risk of penetration into the cerebral cavity, such as the cribriform plate, the ethmoid fovea, the roof of the ethmoidal cells and the lateral walls of the sphenoid sinus [5]. Knowledge of patient anatomy and training for performance of meticulous surgical techniques are very important for avoiding complications [3] [13] [14]. However, even in the hands of well-trained surgeons, complications still occur [2] [3] [14], as happened in our patients: in two of the three cases, surgery was performed only by an experienced surgeon. The prevalence of intracranial complications in our patients was similar to that reported by other authors [1].

In all three cases the complication occurred in the right nostril. This observation has been reported previously [14]. Surgery on the right side for right-handed surgeons presents greater difficulty in terms of visualizing anatomical landmarks and is correlated with an increase in complications [10] [14].

We believe that using an endoscope with a $30^{\circ}$ lens leads to an increased risk of endocranial complications, as it may confuse the perceived height inside the nostril and lead to involuntary penetration into the brain cavity, as in the three cases presented. We do not have Navigation-assisted surgery, but there is evidence from published studies that the use of Navigation-assited surgery for sinus surgery, within selected populations, is associated with a lower risk of major and total complications [15].

The extent of disease must also be considered. Cases with diffuse infectious disease, such as those we present here, involve a higher risk of postoperative complications because they require deeper surgical attention into the

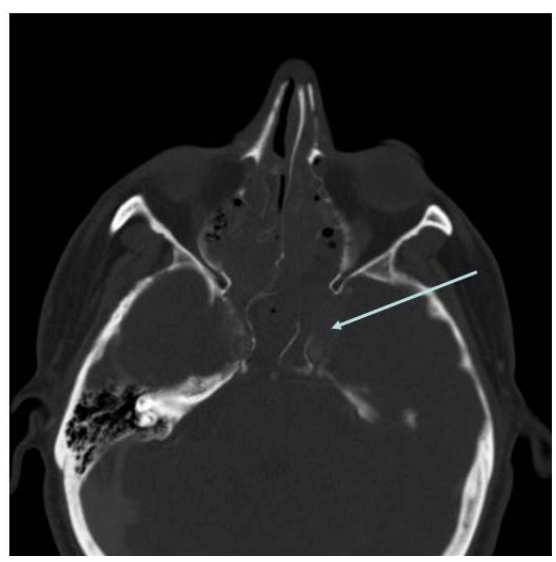

(a)

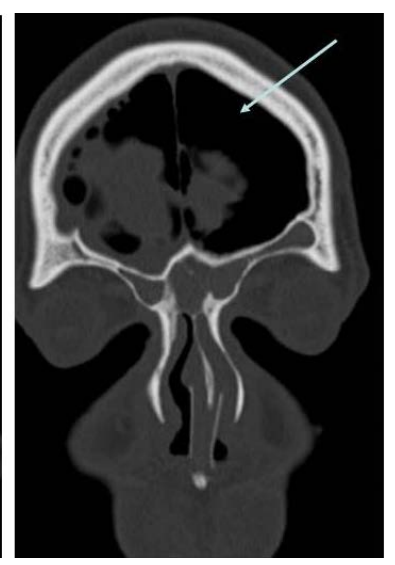

(b)

Figure 3. Patient 3. (a) Axial CT. Pansinusitis with destruction of the lateral wall of the right sphenoid sinus (arrow); (b) Coronal CT. Massive pneumocephalus in the frontal region (arrow). 
endonasal anatomical boundaries near the base of the skull [15]. In addition, these inflammatory lesions bleed diffusely, preventing visual control.

Early recognition and appropriate management of these complications is critical to minimizing the serious consequences that can threaten the life of the patient [2] [3] [7]. In addition, the postoperative period is critical to reducing the risk of permanent damage [2]. Two of our cases illustrate this axiom (patients 1 and 3). However, the case of patient 2 illustrates the fact that complications can occur and appear later; thus, any unusual neurological symptoms in a patient undergoing FESS in previous weeks could indicate an intracranial complication.

A CSF leak is the most frequent endocranial complication [5]. A CSF leak is the communication between the subarachnoid space and the nasal mucosa caused by destruction of the boney plane that separates these spaces. An intraoperative CSF leak is a clear risk factor for intracranial complications. If a CSF leak is recognized intraoperatively, repair should be initiated immediately [2] [10] [14]. However, repair does not always prevent the development of a complication, as occurred in patient number 2. In the immediate postoperative period, we believe that surgical reparation should be the norm, and that patients must be monitored carefully for several weeks post-surgery. Some surgeons advocate placing a lumbar drain and maintaining the patient under observation and bed rest in the semi-seated position [7] [14].

Pneumocephalus is the pathological accumulation of intracranial air from the sinonasal cavity. The pressure gradient between the subarachnoid space and the sinonasal cavities is reversed, which allows air to enter the subarachnoid spaces [16]. Pneumocephalus is characterized by the existence of a dehiscence osteomeningea and rhinoliquorrhea. Pneumocephalus is possible only when the intracranial pressure is lower than the atmospheric pressure. Under normal conditions, fluid tends to exit the fistula until the pressures are inverted. Factors that decrease intracranial pressure, such as the placement of a lumbar drain for a CSF fistula, generate a pressure gradient that favors intracranial accumulation of air and formation of pneumocephalus. Treatments include conservative measures of waiting for spontaneous resolution by resorption or intracranial air drainage. Conservative treatment of fistula has proved insufficient, and so most authors recommend surgical repair [17]. The cribriform plate is the region more frequently associated with iatrogenic pneumocephalus [8]; however, in our patient, the damage was caused by the presence of allergic fungal sinusitis sphenoid involvement and destruction of the side walls of the sinus.

Management of endocranial complications includes treatment with prophylactic antibiotics that cross the blood brain barrier, strict bed rest, head elevation, avoidance of Valsalva maneuvers (coughing, sneezing, nose blowing and straining) that may increase intracranial pressure and performing CT scans and nasal endoscopy control [7]. The collaboration between neurosurgeons and infectious disease specialists is essential.

\section{Conclusion}

In conclusion, predisposing factors for endocranial complications include anatomic abnormalities (even those that appear minimal), severe forms of sinusitis, such as allergic fungal sinusitis and nasal polyposis, and peroperative CSF leaks. Prognosis is favorable with early management and appropriate clinical follow-up, with strong collaboration between neurosurgeons and infectious disease specialists. Brain abscesses in the frontal lobe secondary to a CSF fistula (even when resolved during the operation) can manifest weeks after surgery. Successful management of the major complications of FESS is critical to reduce the risk of permanent injury.

\section{Conflict of Interest}

The authors declare neither conflict of interest nor sources of funding for this work.

\section{References}

[1] Tabaee, A., Kacker, A., Kassenoff, T.L. and Anand, V. (2003) Outcome of Computer-Assisted Sinus Surgery: A 5-Year Study. American Journal of Rhinology, 17, 291-297.

[2] Armengot, M., Gómez-Gómez, M.J. and García-Lliberós, A. (2013) A Simple and Reliable Technique for the Treatment of Rhinoliquorrhoea from Small Defects: Free Nasal Mucosa Overlay Graft. Neurocirugia, 24, 197-203. http://dx.doi.org/10.1016/j.neucir.2013.03.002

[3] Asaka, D., Nakayama, T., Hama, T., et al. (2012) Risk Factors for Complications of Endoscopic Sinus Surgery for Chronic Rhinosinusitis. American Journal of Rhinology \& Allergy, 26, 61-64.

[4] Heaton, C., Goldberg, A.N., Pletcher, S.D. and Christine, M. (2012) Sinus Anatomy Associated Inadvertent Cerebro- 
spinal Fluid Leak during Functional Endoscopic Sinus Surgery. Laryngoscope, 122, 1446-1449. http://dx.doi.org/10.1002/lary.23305

[5] Dalgorf, D.M., Sacks, R., Wormald, P.J., et al. (2013) Image-Guided Surgery Influences Perioperative Morbidity from Endoscopic Sinus Surgery: A Systematic Review and Meta-Analisis. Otolaryngology_Head and Neck Surgery, 149, 17-29. http://dx.doi.org/10.1177/0194599813488519

[6] Ruiz-Juretschke, F., Mateo-Sierra, O., Iza-Vallejo, B. and Carrillo-Yagüe, R. (2007) Neumoencéfalo intraventricular a tensión secundario a cirugía transesfenoidal: presentación de un caso y revisión de la literatura. Neurocirugía, 18, 134-137.

[7] Fokkens, W.J., Lund, V.J., Mullol, J., Bachert, C., Alobid, I., Baroody, F., et al. (2012) European Position Paper on Rhinosinusitis and Nasal Polyps 2012. Rhinology Supplement, 23, 1-298.

[8] Levine, H.L. (1990) Functional Endoscopic Sinus Surgery: Evaluation, Surgery and Follow-Up of 250 Patients. Laryngoscope, 100, 79-84. http://dx.doi.org/10.1288/00005537-199001000-00016

[9] Christopher McMains, K. (2008) Safety in Endoscopic Sinus Surgery. Current Opinion in Otolaryngology \& Head and Neck Surgery, 16, 247-251. http://dx.doi.org/10.1097/MOO.0b013e3282fdccad

[10] Lund, V.J., Stammberger, H., Nicolai, P., Castelnuovo, P., Beal, T., Beham, A., et al. (2010) European Position Paper on Endoscopic Management of Tumours of the Nose, Paranasal Sinuses and Skull Base. Rhinology Supplement, 22, 1-143.

[11] Maier, W. and Laszig, R. (2003) Complications of Endonasal Paranasal Sinus Surgery-Diagnostic and Therapeutic Consequences. American Journal of Rhinology, 17, 291-297.

[12] Maniglia, A.J. (1989) Fatal and Major Complications Secondary to Nasal and Sinus Surgery. The Laryngoscope, 99, 276-383.

[13] Maniglia, A.J. (1991) Fatal and Others Major Complications of Endoscopic Sinus Surgery. The Laryngoscope, 101, 349-354.

[14] Ortega, P., Gómez-Ullate, J. and García-Polo, J. (2001) Complicaciones de la cirugía endoscópica nasosinusal. In: Bernal, M., Massegur, H., Sprekelsen, C., Ademá, J.M., Fabra J.M. and Moina, H., Eds., Cirugía Endoscópica Nasosinusal Básica y Avanzada, Gràfiques Alzamora, Girona, 257-279.

[15] Reyt, E., Righini, C., Schmerber, S. and Karkas, A. (2011) Rhinorrhées cérébrospinales. EMC, Elsevier Mason SAS, Paris, Oto-rhino-laryngologie, 20-365-A-10.

[16] Ulualp, S.O. (2008) Complications of Endoscopic Sinus Surgery: Appropiate Management of Complications. Current Opinion in Otolaryngology \& Head \& Neck Surgery, 16, 252-259. http://dx.doi.org/10.1097/MOO.0b013e3282fdc3b2

[17] Stankiewicz, J.A. (1987) Complications of Endoscopic Intranasal Ethmoidectomy. The Laryngoscope, 97, $1270-1273$. http://dx.doi.org/10.1288/00005537-198711000-00004 
Scientific Research Publishing (SCIRP) is one of the largest Open Access journal publishers. It is currently publishing more than 200 open access, online, peer-reviewed journals covering a wide range of academic disciplines. SCIRP serves the worldwide academic communities and contributes to the progress and application of science with its publication.

Other selected journals from SCIRP are listed as below. Submit your manuscript to us via either submit@scirp.org or Online Submission Portal.
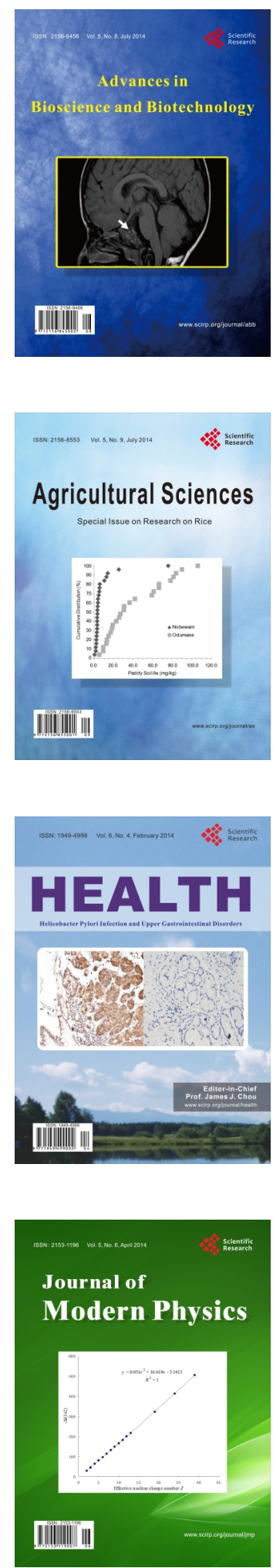
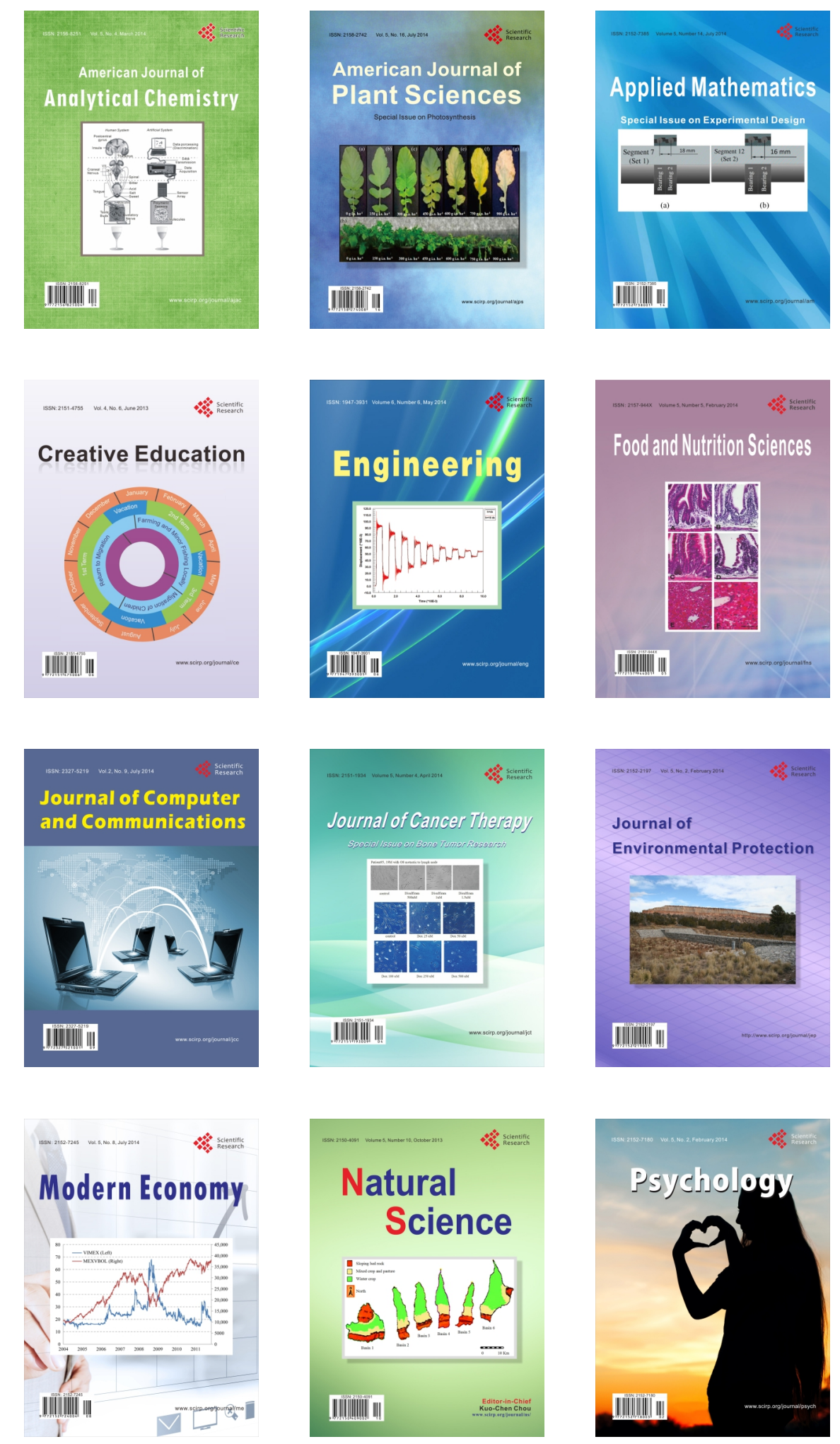